Finisterra, L, 100, 2015, pp. 35-40 doi: 10.18055/Finis7860

\title{
UM ESPAÇO QUE NÃO É
}

Pedro Calapez ${ }^{1}$

Pedro Calapez, vive e trabalha em Lisboa (1953). Começou a expor nos anos setenta tendo realizado a sua primeira exposição individual em 1982. Expôs individual e colectivamente em diversas Galerias de Arte e Museus, em Portugal e no estrangeiro e está representado em várias colecções públicas e privadas. Colabora regularmente com arquitectos desenvolvendo trabalhos de arte específicos ou obras de arte pública. Estudou na Faculdade de Belas Artes de Lisboa. URL: http://www.calapez.com. E-mail: pcalapez@gmail.com 


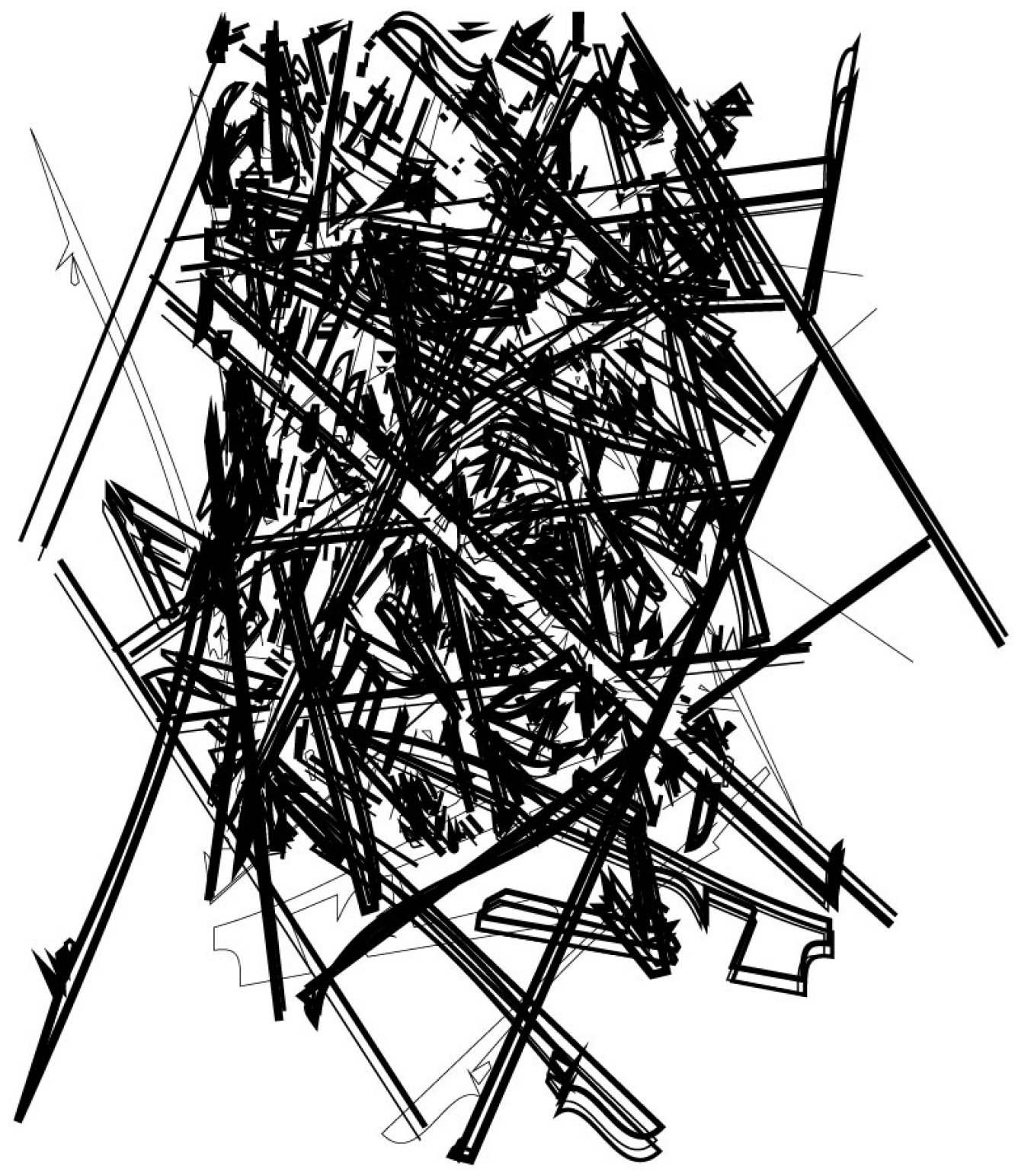



12 (1) 1. 4 - o W 1010 D -

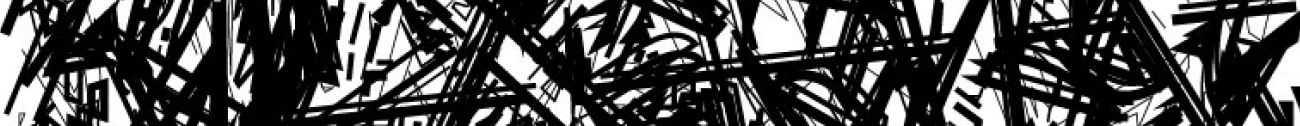
- J 1 J H A

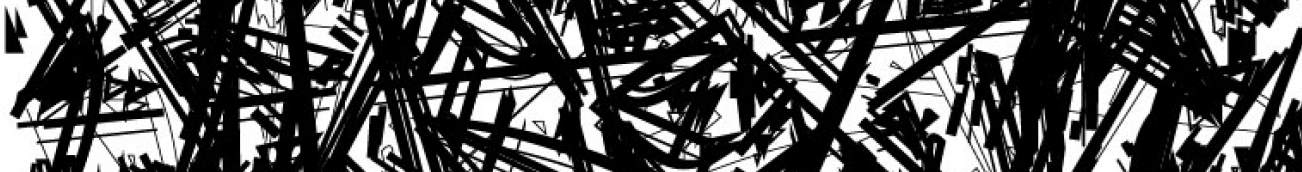
M $/ 2 \quad 1,1$ A (T) N

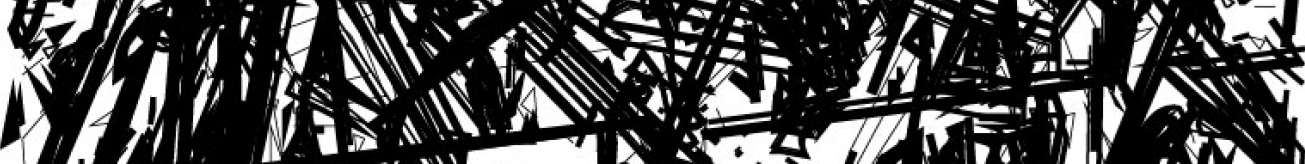
14 W

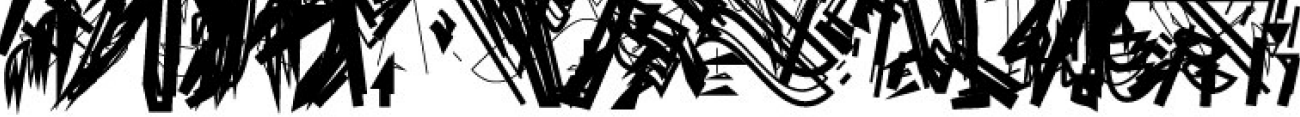

o espaço na distância - como recuperar - experiência e exaustão - afastar-me, para depois me aproximar - duplo destino - saber olhar - modelo imaginado - não vos posso ajudar - desencontro - extensão panorâmica - iludir o espírito da paisagem - momento isolado - imenso catálogo - perturbação nas escolhas - como viver o horizonte - construir espaço - entre tudo e nada - o silêncio ocupa um intervalo - eco de murmúrios - e por vezes sinto medo. 


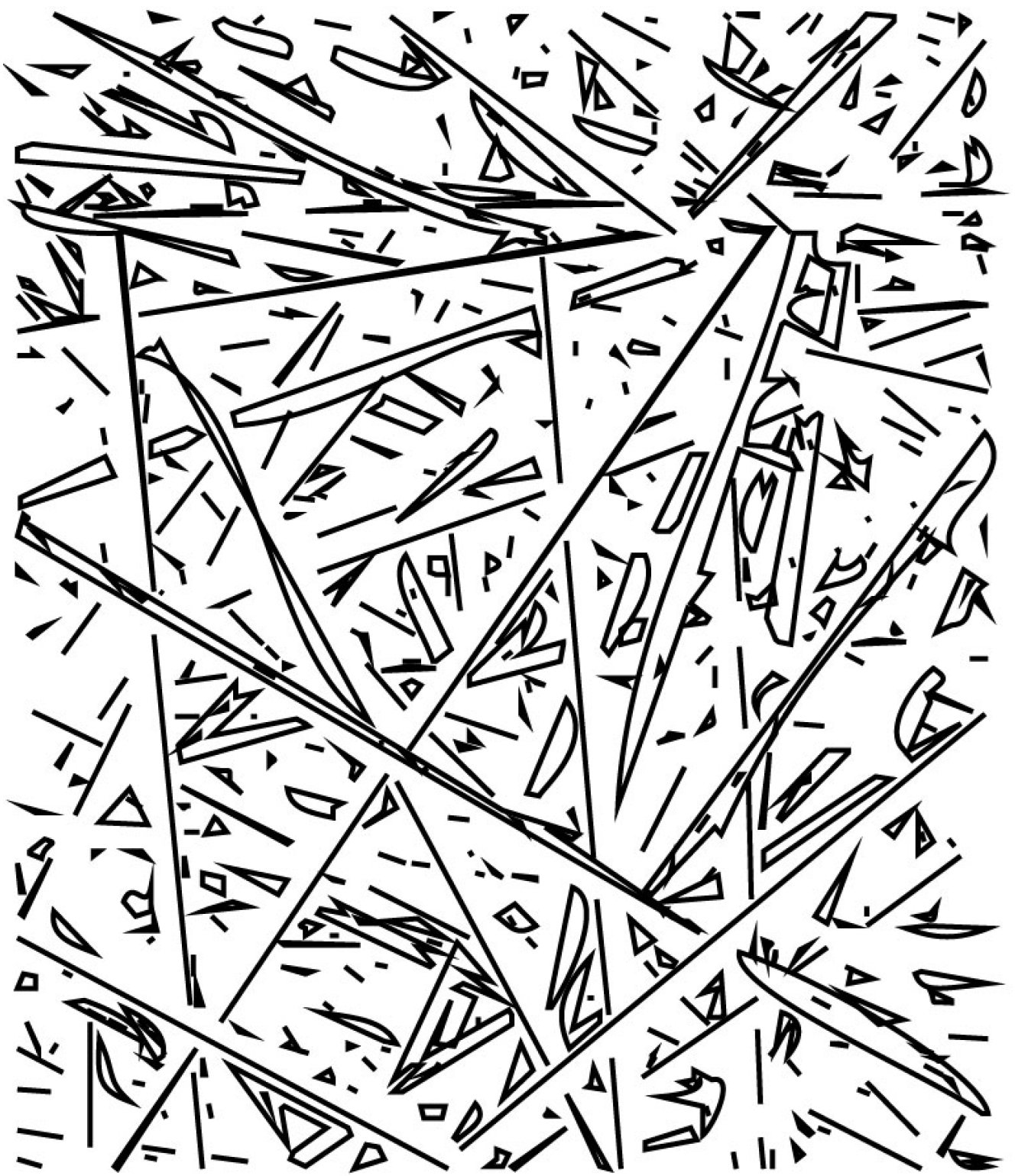

as estações mortas, o presente, a aurora - o passante olha sem parar - o detalhe desvanece-se - só ver completamente - totalidade - nada sei da vida e da morte - "Não te parece que a brisa que aqui corre resulta suave e perfumada"?

O caminho que a lado nenhum leva parece prometer um espaço, um espaço inacessível pois no fim desse caminho não chegaremos a lado nenhum - do bloqueio físico seguimos para um espaço virtual pois só aí poderemos continuar. 


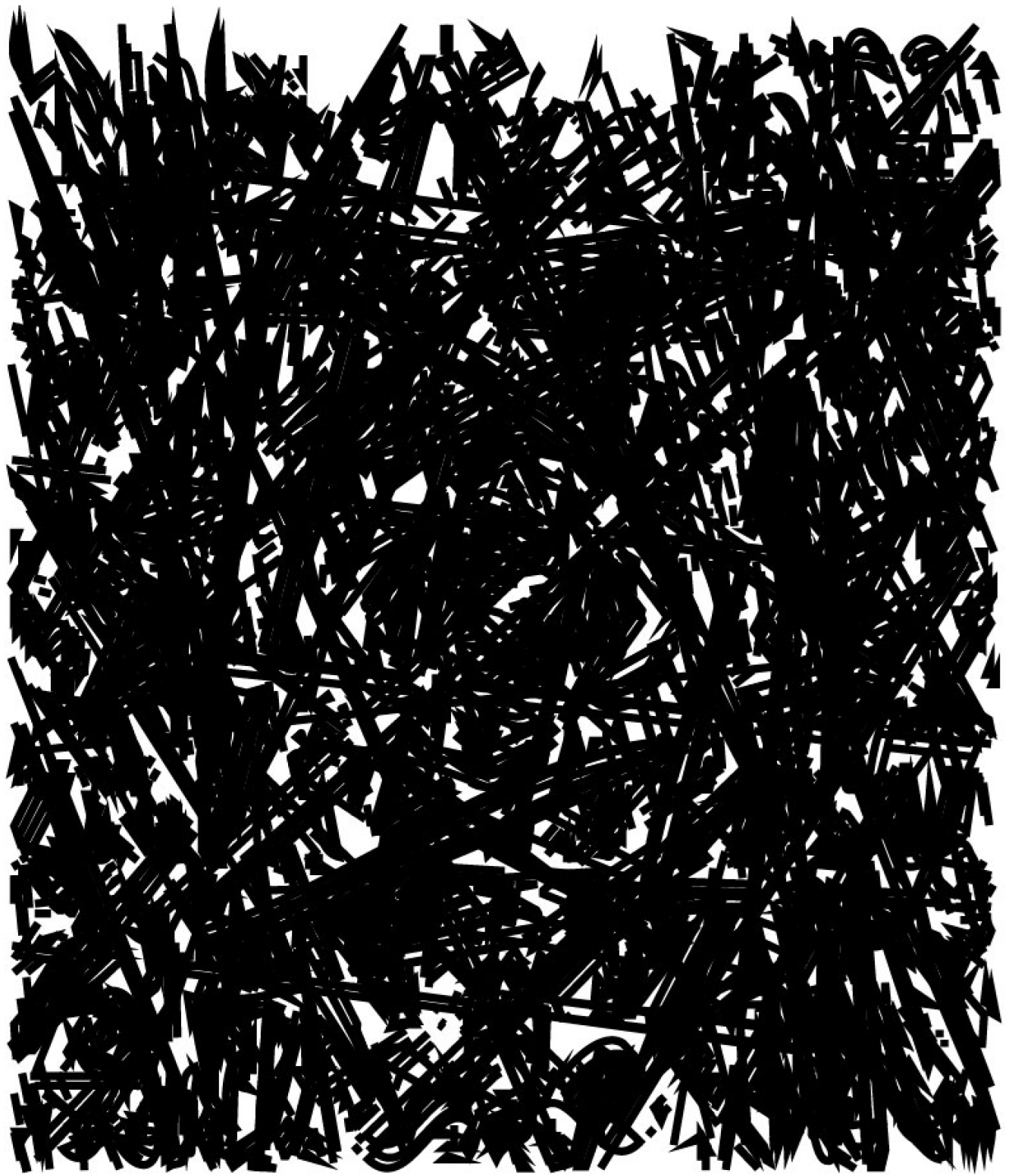

inicia-se por uma descida - deslizamos lentamente - os espinhos da amoreira silvestre raspam nas nossas faces - os sapatos enfiam-se no pó do chão que se levanta em pequenas nuvens - uma simulada tempestade de areia sobe junto aos nossos pés. As nuvens desfazem-se em pequenas ondas qual tsunami sem consequências a não ser a suave ilusão de caminhar sem um chão - vemo-nos a flutuar e somos suavemente empurrados pelo vento - desconheço para onde somos levados. o perdeu os seus contornos e só de tempos em tempos o vislumbramos - a ribeira lá longe contorna os montes - e continuamos - passamos por cima da floresta dos eucaliptos que nos incensam com o seu perfume. indeterminamos o espaço em que agora nos encontramos. 


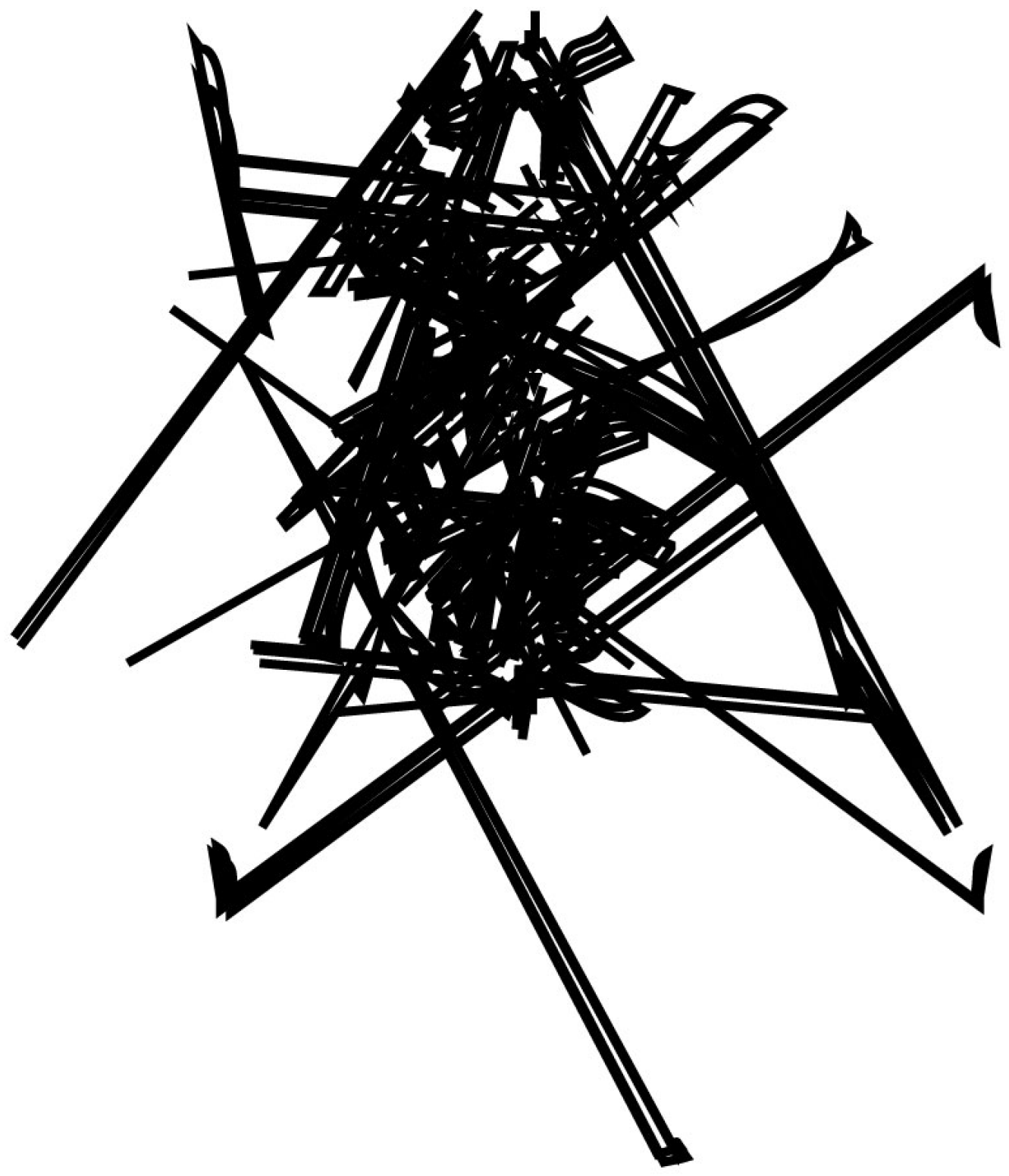

Porque o espaço fora da cidade, fora da história,

é um espaço de encanto, de rapto, e o cenário que então nos aparece

é o arquétipo que nos conduz ao centro da interioridade.

Raffaele Milani, Larte del paessaggio 